\title{
The performance of an accelerated drying system for drying of skim natural rubber laces
}

\author{
S Siriwardene*, P H Sarath Kumara** and U M S Priyanka* \\ * Rubber Research Institute of Sri Lanka, Telawala Road, Ratmalana, Sri Lanka \\ ** Lalan Rubbers (Pvt.) Ltd.
}

Received 29 February 2012; Accepted 28 May 2012

\begin{abstract}
A dryer consisting of a saw dust fed furnace and a drying chamber was designed and fabricated for drying of skim natural rubber laces using hot smoke. Uninterrupted drying of laces was carried out in warm smoke in three different temperature ranges. Drying performance was evaluated in terms of raw rubber properties and drying period to achieve complete dryness. Quality of laces was assessed by visual appearance. The best temperature range for drying of skim natural rubber laces was found to be $30-34{ }^{\circ} \mathrm{C}$. Drying efficiency of laces was accelerated by more than $60 \%$ without affecting its raw rubber properties when laces were dried at this temperature range. The resistance to mould growth of dried laces was also improved. However, the dried product was downgraded according to the visual quality assessment in terms of colour which is commonly practiced in the trade for grading of rubber. Therefore, heating mechanism was modified to provide a draft of clean warm air into the drying chambers where the laces were hung for drying. The drying temperature inside the chambers was maintained at the selected temperature range $\left(30-34{ }^{\circ} \mathrm{C}\right)$ and drying of laces was completed within twenty-four hours. It was able to obtain skim laces with improved colour. Drying curve for skim laces dried using accelerated drying system was derived. Results of tests carried out to determine the raw rubber properties of laces showed that raw rubber properties of skim laces were not affected due to accelerated drying within the selected temperature range. Mechanical and physical properties of 80/20 (w/w) blends of Technically Specified Rubber (TSR 20)/ambient air dried skim laces and the blends of TSR (20)/warm air dried skim laces were also compared. The properties studied were tensile properties, hardness, compression set and resilience. The results suggest that warm air drying of skim laces has no significant effect on the mechanical and physical properties of the blends of TSR/skim laces.
\end{abstract}

Key words: natural air drying, raw rubber properties, skim natural rubber laces, vulcanizate properties, warm air drying 


\section{Introduction}

In 2010, Sri Lanka produced 152,980 MT of natural raw rubber of which 24,350 MT were produced in the form of centrifuged latex (Anon, 2010). This amounted to about $16 \%$ of the total local rubber production. The rest of the rubber was produced in the forms of Ribbed Smoked Sheet (RSS) (39\%), Crepe Rubber (CR) (39\%) and Technically Specified Rubber (TSR) $(6 \%)$. In the manufacture of centrifuged latex about $55 \%$ of the volume of field latex ends up in skim latex which contains approximately $4 \%(\mathrm{w} / \mathrm{w})$ dry rubber. Skim latex is coagulated and conventionally converted into skim crepe laces following the conventional crepe rubber manufacturing process. This skim rubber is considered a value added byproduct from the centrifuging process, (Seneviratne et. al., 2003). It can be estimated that approximately $7 \mathrm{~kg}$ of skim rubber could be recovered from each $100 \mathrm{~kg}$ of centrifuged latex produced. Eventhough, the manufacturing processes of skim crepe and latex crepe are basically very similar, their composition and drying procedures are different (Bristow, 1990). Skim rubber has a high content of non rubbers including proteins (approximately 15\%), metal ions such as copper and iron and residue of preservative systems. Crepe laces which are almost free from above non rubber components are dried in conventional drying towers in a draft of warm air at $34^{\circ} \mathrm{C}$ under control conditions. Skim laces are normally dried in ambient air without any control. Drying characteristics of crepe laces have already been established by Tharmalingam et al. (1977). Work carried out by them has shown that initial moisture content is $7-12 \%$ and that the final moisture content is approximately $0.35 \%$ when dried at $34^{\circ} \mathrm{C}$ for three days with intermittent interruptions to the drying process. Solar assisted drying of crepe rubber laces too has drawn attention by many researchers (Jolly, 1987, Walpita et al., 1984). The results of the studies carried out have shown that utilization of solar energy could be effective, only if the operational practices of drying of crepe laces are changed to minimize drying interruptions and to carry out the operation continuously in the day time during which solar energy could be utilized effectively. Solar flat plate air collectors have been used in RSS drying in Malaysia and Indonesia (Rao, 1985: Monerasingha, 1985: Mohd. 1991; Silbian, 1990. Breymayer, 1993). In each system, flat plate air collectors have been used to generate heated air before it is passed to the drying chamber. Recently, an efficient drying system has been introduced for drying of sheet rubber to dry sheets in a single day, cutting down the drying period of conventional drying period by $80 \%$ (Siriwardena et al., 2008).

However, for skim rubber, there is neither established controlled drying system nor established drying characteristics so far, available in the 
literature. Due to the high investment, economic and technological reasons, the conventional hot water-boiler-radiator crepe rubber drying system is not used for drying of skim laces. They are dried in natural air with no induced heating and therefore, have many inherent disadvantages. It takes about 3-4 days during dry weather and 10-14 days during wet weather for drying of laces. The laces are subjected to downgrading due to mould growth, discolouration and dirt contamination. In addition, prolonged drying time results in a long production cycle and therefore, restricts the cash flow of the business while requiring an extensive space for hanging laces and making drying process a very labour intensive operation. Quality inconsistencies of laces are frequently observed due to the uncontrolled drying process particularly during rainy season. If a controlled drying system is introduced to shorten the drying period to a considerable level, most of the above problems could be eliminated or minimised. Attempts could also be made to produce thicker sheets or mat reducing the electrical power consumed for milling with simultaneous increase in the output of the mills, i.e. improved productivity.

Therefore, it has become an industrially important endeavour to develop an economical accelerated drying system for drying of skim crepe laces without affecting the properties of the dried product and establish the drying characteristics of skim rubber. In this study, a cost effective and accelerated drying system which is similar to the dryer developed by Siriwardena et al. for RSS was designed and fabricated for drying of skim rubber laces. Drying performance and the properties of the dried products were also compared with the conventionally dried skim rubber. Mechanical and physical properties were studied using a blend of TSR/skim $(80 / 20)$, since it has been reported in the literature that using a 80/20 (TSR/skim) blend, comparable properties to $100 \%$ TSR could be obtained (Bristow, 1990).

\section{Materials and Methods Materials}

A model drying unit with a capacity of $600 \mathrm{~kg}$ was designed and constructed at Lalan Centrifuged Latex Factory at Bulathsinhala. The dryer consisting of a compact enclosure, a fixed rack system to hang laces and a system for a vertical hot air draft was fabricated. A saw dust burner was introduced as the heat source. A perforated metal plate (gauge 20) was introduced above the furnace to pass heat and smoke to the drying chamber. However, during the modification, the perforated metal plate was replaced with a solid metal plate to provide only the heat into the drying chamber by conduction through the plate and to prevent the exposure of laces to smoke. The horizontal smoke outlets were provided at the top of the furnace wall opposite the furnace door which was constructed with adjustable air inlets on it. An adjustable air ventilation duct was fixed at the top of the drying chamber. Adjustable air inlet ducts were fixed at the bottom of the 
chamber to facilitate air flow into the drying chamber.

Skim crepe laces were manufactured according to the standard manufacturing procedure at Bulathsinhala centrifuged latex plant belonging to Lalan Rubber (Pvt.) Ltd. Weight of wet laces varied between $1 \mathrm{~kg}$ to $1.2 \mathrm{~kg}$ with a thickness of $0.5 \mathrm{~mm}$.

\section{Experimental procedure}

Skim laces were hung in the drying chamber. Warm smoke was then supplied using the saw dust burners and the temperature of the drying chamber was recorded at specified time intervals. Three temperature ranges were studied to establish a suitable temperature range for drying of skim laces. After the modification, heat was provided with no smoke to the drying chamber. The weights of laces were recorded on an hourly basis. A few skim laces were dried at ambient temperature for the purpose of comparison.

The raw rubber properties of five fast dried samples at selected temperature range $\left(30-34{ }^{0} \mathrm{C}\right)$ were compared with conventionally dried skim laces taken from the same source of wet laces. Testing of raw rubber properties of dried laces was carried out following the respective ISO standards given in Table 1. A compound from a blend of TSR/Skim rubber (80/20) was prepared using the formula given in Table 2. It was used to study the effect of drying system on the mechanical properties of the blends of TSR/skim rubber.

Table 1. Standard test methods used to determine the raw rubber properties

\begin{tabular}{ll}
\hline $\begin{array}{l}\text { Raw rubber } \\
\text { property }\end{array}$ & ISO No. \\
\hline $\begin{array}{l}\text { Initial Wallace } \\
\text { plasticity (P0) }\end{array}$ & ISO 2007-1991 (E) \\
$\begin{array}{l}\text { Plasticity Retention } \\
\text { Index (PRI) } \\
\% \text { of volatile matter }\end{array}$ & ISO 2930-1986 (E) \\
$\begin{array}{l}\text { IVM }) \\
\text { Raw Mooney }\end{array}$ & ISO 289-1979 (E) \\
viscosity & \\
$\begin{array}{l}\text { Dirt } \\
\text { Lovibond colour }\end{array}$ & ISO 249-1974 (E) \\
\hline
\end{tabular}

Table 2. Formula used for compounding of the blend of sheet rubber and skim rubber

\begin{tabular}{lc}
\hline Chemicals & Parts per hundreds (Phr) \\
\hline Technically Specified Rubber (TSR) & 80 \\
Skim Rubber & 20 \\
CBS & 0.5 \\
Zinc Oxide & 5.0 \\
Stearic acid & 2.0 \\
Carbon black (HAF) & 50.0 \\
Processing oil (Dutrex 729) & 5.0 \\
Anti-Oxidant & 2.0 \\
Sulphur & 2.5 \\
\hline
\end{tabular}


Accelerated drying of skim crepe laces

\section{Preparation of NR/Skim blends \\ Mixing procedure}

Mastication of NR and skim and mixing of other ingredients were carried out on a laboratory scale two-roll mill (David Bridge \& Co. Ltd., England). NR was masticated for two minutes and skim rubber was added and mastication was continued for further one minute. Other ingredients were added subsequently. Sulphur which was the curing agent was added last.

\section{Cure characteristics}

The cure characteristics of the blends were measured on an oscillating disc Rheometer (ODR) (Rheo-Line Oscillating Disc Rheometer, Prescott Instruments Ltd., UK) at arc 0.5 degree according to ASTM 2084. For preparation of test pieces, the compounds were moulded and vulcanized to the optimum cure, in a hydraulic hot press (Yeji Corporation, England) maintained at $150{ }^{\circ} \mathrm{C}$ and at a pressure of $20 \mathrm{MPa}$.

\section{Tensile properties}

Tensile tests were carried out according to ASTM D412 on Monsanto Tensometer at a cross head speed of $500 \mathrm{~mm}$ min-1. Dumbbell shape specimens of $2.0 \mathrm{~mm}$ thickness were cut from a moulded sheet with the aid of a Wallace die cutter. Modulus at 300\% elongation, tensile strength and elongation at break were measured.

\section{Tear strength}

The tear strength was tested according to ASTM D 624 using crescent type specimens which were cut from the moulded sheet with the aid of Wallace die cutter. The test was carried out using a Monsanto Tensometer at a cross head speed of $50 \mathrm{~mm}$ min-1.

\section{Rebound resilience}

Resilience was measured according to ISO 4662 using Lupke pendulum. The rubber specimens were tested by bouncing the pendulum against the specimen. Three pieces were tested. The reading was expressed as a percentage and the median value was taken.

\section{Compression set}

Specimens used were disc type, $12.5 \pm$ $0.5 \mathrm{~mm}$ thick. They were tested according to ASTM D 395 using a compression device consisting of three plates. The space between two plates had a thickness of $9.5 \pm 0.2 \mathrm{~mm}$.

\section{Hardness}

Durometer IRHD hardness test was carried out according to ASTM D 2240. Disc type samples were used and three readings were obtained at three points on the test piece. Three pieces were used for the test and the average of the results was taken.

\section{Determination of mould growth}

Mould growth of the samples was examined at $100 \%$ humidity and at ambient temperature. Minimum time 
taken to observe the mould growth was recorded.

\section{Results and Discussion Dryer performance}

Raw rubber properties of skim laces dried at three different temperature ranges using hot smoke (first stage of experiment) and the skim laces dried in natural air are shown in Table 3 along with the visual observations and the time taken to bring the moisture content below 1.0 - 1.5 (wb)\%.

According to the results shown in the Table 3, drying of laces above $40{ }^{\circ} \mathrm{C}$ in hot smoke has resulted in oxidative degradation of laces as evident from melted surfaces of the laces and the impossibility of completing the PRI test due to the melting of the test pieces at the ageing temperature $\left(140^{\circ} \mathrm{C}\right)$. Drying of laces at other two temperature ranges had no adverse effect on PRI value and also no changes of surface appearance except the darker colour of the laces due to smoking. Drying at higher temperature range $\left(35-39^{\circ} \mathrm{C}\right)$ has obviously accelerated the drying process. However, there might be a risk of oxidative degradation (melting). Since the laces could be dried in less than a day with no signs of melting when the laces were dried at a temperature range of $30-34{ }^{\circ} \mathrm{C}$, this temperature range was chosen for the accelerated drying of the skim laces. The operational practices to maintain the temperature at the required range are easy and the possible heat losses from the drying chamber to the environment are also reduced when the lower temperature range is used.

Table 3. Drying performance of skim laces at different temperatures

\begin{tabular}{|c|c|c|c|c|c|}
\hline $\begin{array}{l}\text { Temperature } \\
\text { range }{ }^{\circ} \mathrm{C}\end{array}$ & $\begin{array}{l}\text { Plasticity } \\
(\mathrm{Po})^{*}\end{array}$ & $\begin{array}{l}\text { Plasticity } \\
\text { Retention } \\
\text { Index } \\
(\text { PRI \%)* }\end{array}$ & $\begin{array}{l}\text { Drying } \\
\text { period } \\
\text { (hours) }\end{array}$ & $\begin{array}{c}\text { Mould } \\
\text { Growth rate } \\
\text { at } 100 \% \\
\text { Humidity } \\
\text { (no. of hrs) }\end{array}$ & Visual observations \\
\hline $30-34$ & 60 & 42 & $20-24$ & 36 & $\begin{array}{l}\text { Darker colour than } \\
\text { in conventionally } \\
\text { dried laces }\end{array}$ \\
\hline $35-39$ & 54 & 38 & $18-20$ & 32 & $\begin{array}{l}\text { Darker colour than } \\
\text { the conventionally } \\
\text { dried laces }\end{array}$ \\
\hline $40-45$ & 43 & - & $18-20$ & 30 & Laces melted \\
\hline $\begin{array}{l}28-30 \\
\text { Ambient air } \\
\text { drying }\end{array}$ & 58 & 40 & $72-96$ & 24 & Nil \\
\hline
\end{tabular}

* Average values 
However, the rubber laces dried even at this temperature range of $30-34{ }^{\circ} \mathrm{C}$ was downgraded according to the visual grading system practiced under the local marketing norms due to the exposure of the laces to smoke during the drying process using hot smoke. Therefore, a perforated metal plate fixed just above the saw dust burner was replaced with a solid metal plate to prevent the hot smoke entering the drying chamber where the laces were hung. Heat was then provided only by the conduction and radiation through the metal plate. Laces were then dried at the selected temperature range $\left(30-34^{\circ} \mathrm{C}\right)$ after modification of the drying system to prevent the smoke getting in to the drying chamber where the rubber laces were being dried.

\section{Drying characteristics of skim natural rubber laces}

Figure 1 shows the ambient temperature and temperature profile of drying chamber while Figure 2 shows the two drying curves derived for laces hung at an upper location and a middle location using the weight loss data of the laces dried in warm air $v s$. drying time. It could be seen from temperature profile of the modified system that the temperature of the new system could be maintained at a narrow temperature range $\left(30-34{ }^{\circ} \mathrm{C}\right)$, a few degrees above the ambient temperature. As it could be seen in the raw rubber properties and vulcanizate properties discussed below, the drying of laces in a narrow temperature range above the ambient temperature has not affected the raw rubber and the vulcanizate properties of the TSR/skim rubber blend.

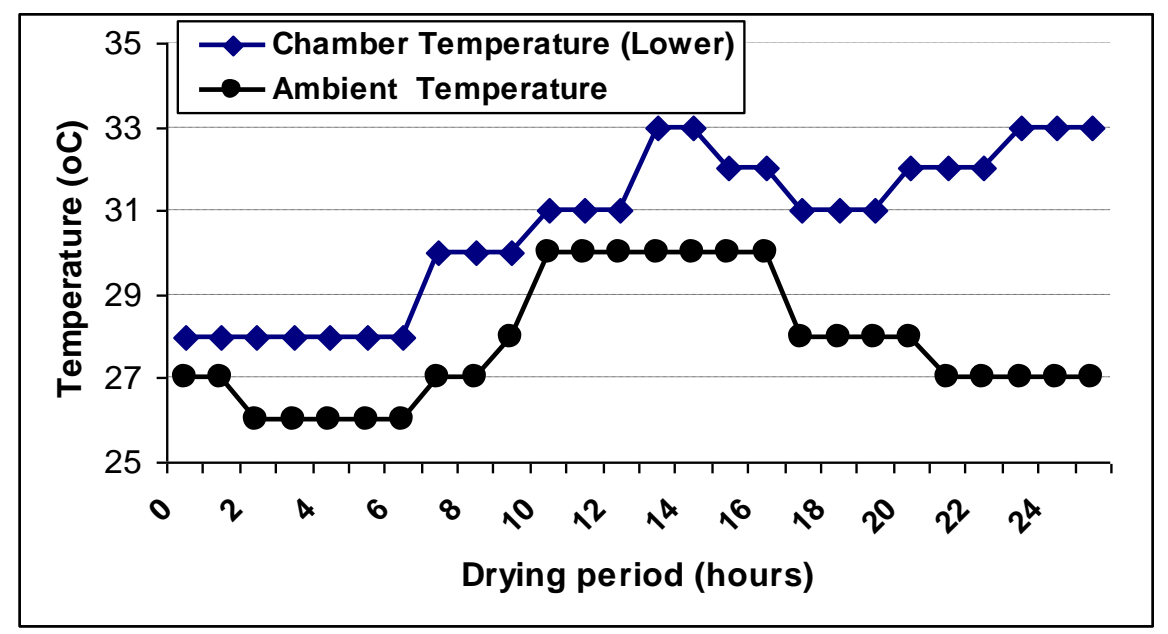

Fig. 1. Temperature profiles in the drying chamber and ambient air 


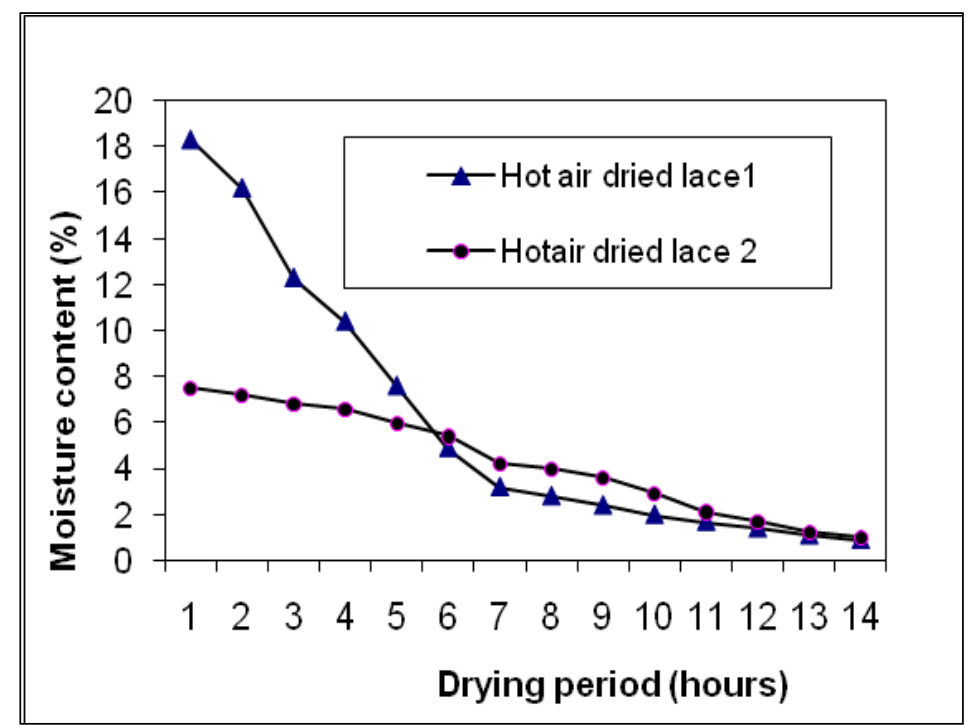

Fig. 2. Weight loss $v s$. drying time for two skim laces (warm air dried)

From Figure 2, it is clearly evident that the drying system introduced has reduced the drying time of skim laces from 3-4 days to less than a single day offering a reduction of more than 66$75 \%$ of total drying period and also the space requirement for drying while improving the cash flow of the business. These benefits will be significantly higher when drying is done in rainy weather as natural air drying is taking more than ten days to dry the rubber to a constant moisture level. Therefore, this accelerated drying system offers advantages to the skim rubber processing industry in many folds. The drying curve derived for skim laces dried using this drying system is very similar to the typical drying curves of agricultural products (Mahendra, 1987). This accelerated drying system shows the following two typical regions similar to those in the drying curves derived for other agricultural crops.

a: Initial drying period where the drying rate and the moisture removal is predominant and is generally referred to as constant rate period of the drying curve. During this period internal resistance to transport moisture is much less significant than the external resistance to water vapor removal from the surface of laces. Therefore, the moisture removal in this region is governed by all three factors namely air flow rate, temperature and the humidity of the inlet air.

b: Subsequent removal of internal moisture from the laces is quite slow and this regime is referred to as 
falling rate period of the drying curve. During this period, the internal resistance to transport of moisture is significant than the external resistance to water vapour removal from the surface of the laces. Therefore, drying rate in falling rate period is mainly governed by the drying temperature and humidity. In this study, it could be considered that there was no considerable variation in the humidity as the experiments were carried out at the same location. Drying characteristics derived from this experiment is summarized in Table 4.

\section{Raw rubber properties}

Dirt is the foreign matter which are the contaminants getting mixed with rubber during collection and processing while ash is a mixture of metal oxides present in the residue after the rubber is incinerated. Both methods of drying do not have a significant effect on the above properties unless laces are exposed to air born dirt particles due to irresponsible air drying. Therefore, only four raw rubber properties namely $\mathrm{P}_{0} \&$ PRI, moisture content and Mooney viscosity which could be affected by the method of drying were tested. Variation of raw rubber properties in a wide range makes skim rubber to be considered a relatively inferior quality raw material (Brostow, 1990). Five sets of warm air dried and ambient air dried skim laces collected from same source were analyzed for the raw rubber properties. Five samples from each set with different manufacturing dates were used in this study and the results are presented in Table 5. No significant variation in raw rubber properties was observed in the warm air dried skim rubber compared with that of the ambient air dried ones. However, the resistance of warm air dried laces to thermal oxidation as measured by PRI showed lower values than that of the ambient air dried laces. It is however, not significant when wide variation of raw rubber properties of normal skim laces are considered. This suggests that naturally occurring antioxidants were not subjected to a severe decomposition at the selected range of drying temperature. Final moisture content (VM) of the laces was found to be higher than the moisture content reported immediately after the completion of drying as seen in the respective drying curves. This may be due to the re-absorption of moisture from the environment during storage as the skim laces have a higher content of hygroscopic non rubber substances. 
Table 4. Drying characteristics of skim crepe rubber laces

\begin{tabular}{lcc}
\hline Factor & \multicolumn{2}{c}{ Value } \\
\cline { 2 - 3 } & Ambient air dried & Hot air dried \\
\hline Initial moisture content $(\% \mathrm{wb})$ & $7-18$ & $7-18$ \\
Drying temperature $\left({ }^{\circ} \mathrm{C}\right)$ & $28-30$ & $30-34$ \\
Critical moisture content $(\% \mathrm{wb})$ & $3-4$ & $3-4$ \\
Drying period $($ days $)$ & $3-4$ (dry weather) & 1 \\
Falling rate period $(\%$ of total drying period) & $>75$ & $>75$ \\
Final moisture content $(\%$ wb) & 1.5 & 1.5 \\
\hline
\end{tabular}

Table 5. Raw rubber properties of skim rubber laces dried using warm air and ambient air

\begin{tabular}{|c|c|c|c|c|c|c|c|c|}
\hline \multirow[b]{2}{*}{ Sample No. } & \multicolumn{4}{|c|}{ Ambient air dried samples } & \multicolumn{4}{|c|}{ Warm air dried samples } \\
\hline & $\mathrm{P} 0$ & PRI & VM & VR & $\mathrm{P} 0$ & PRI & VM & VR \\
\hline Sample 1 & 61 & 49.4 & 2.93 & 101 & 58.9 & 33.1 & 2.92 & 102 \\
\hline Sample 2 & 57.1 & 36.6 & 2.71 & 100.5 & 56.4 & 31.2 & 2.7 & 101 \\
\hline Sample 3 & 59.3 & 62.2 & 3.25 & 103 & 58.1 & 33.9 & 2.78 & 99 \\
\hline Sample 4 & 59 & 48.4 & 2.9 & 99.5 & 59.1 & 44.5 & 2.49 & 99 \\
\hline Sample 5 & 59.4 & 42.7 & 3.3 & 98.5 & 57.6 & 25.5 & 2.7 & 99 \\
\hline
\end{tabular}

Cure characteristics and mechanical properties of NR/skim blends

Rheographs of blends of pure NR with skim rubber dried in natural air and warm air are given in Figure 3 (a) and Figure 3 (b). Rheological properties are tabulated in Table 6 . Both rheographs show similar cure characteristic behavior which has the typical S shape of the normal natural rubber compounds. This suggests that the mode of drying has no effect on the curing behavior.

Table 6. Cure characteristics of natural air dried and warm air dried skim crepe laces

\begin{tabular}{lcc}
\hline Rheological properties & Ambient air dried samples & Warm air dried samples \\
\hline Maximum torque $\left(\mathrm{lb} / \mathrm{in}^{2}\right)$ & 4.15 & 5.11 \\
Minimum torque $\left(\mathrm{lb} / \mathrm{in}^{2}\right)$ & 1.95 & 1.69 \\
tS2 $(\mathrm{s})$ & 3.95 & 3.69 \\
t90 $(\mathrm{s})$ & 260 & 206 \\
\hline
\end{tabular}


Accelerated drying of skim crepe laces

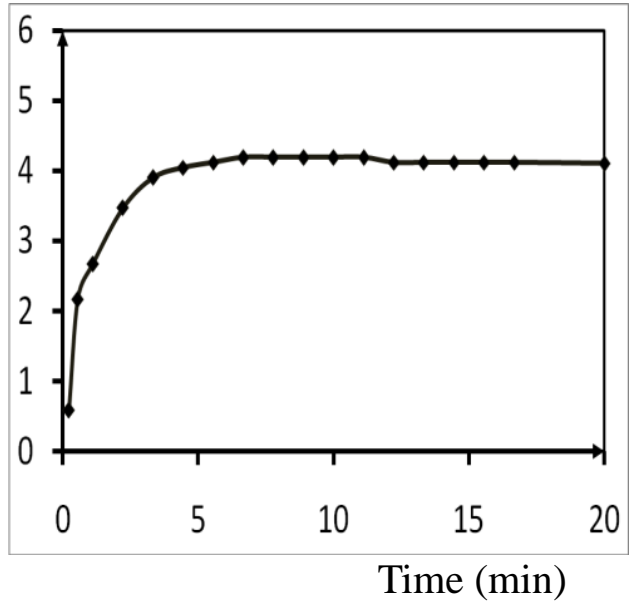

(a)

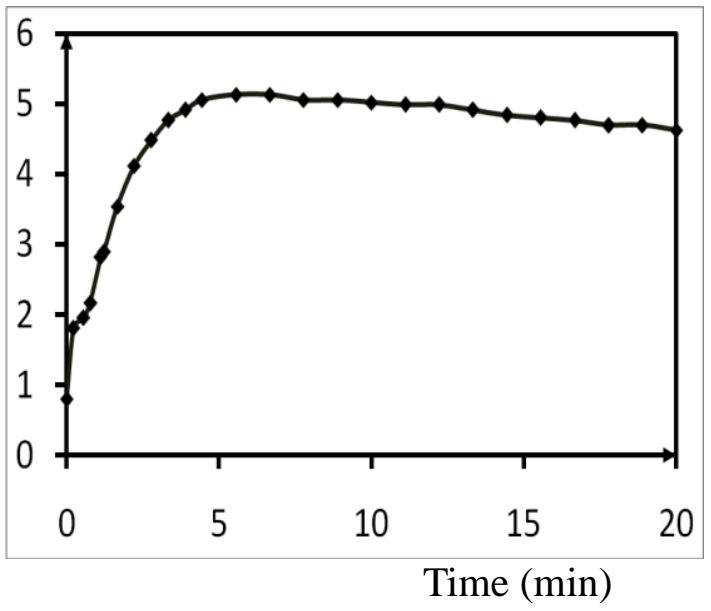

(b)

Fig. 3. Rheograph of blends of TSR/Skim laces (a: Ambient air dried skim laces/TSR blends; b: warm air dried skim laces/TSR blends)

Cure characteristics of a rubber compound mainly depends on the type of polymer and other compounding ingredients in the recipe in addition to the curing system and curing conditions used. Since skim rubber was dried only at a few degrees above the ambient temperature, there may have been no change in the composition of the non rubber constituents which have influence on the cure characteristics of the compound. It could be seen that scorch time, expressed as $\mathrm{tS}_{2}$ on the rheograph, was very short for both rubber compounds (Table 6). Therefore, it is impossible to use these rubbers in product manufacturing process without an adjusted formula i.e. in practical formulations. However, comparable cure characteristics obtained for both blends revealed the independence of the cure characteristics from the drying systems used for drying of skim laces. It has been reported that cure characteristics of skim rubber differs most obviously from normal natural rubber due to the comparatively lower content of non rubbers in the latter. In fact, skim rubber is rich with various other organic chemicals such as amine compounds, proteins and metal ions (Brostow-1990). This could be responsible for the shorter scorch time and higher rate of vulcanization observed, as amine compounds and metal oxides accelerate the vulcanization reaction. 
S Siriwardene $\mathrm{et} \mathrm{al}$.

\section{Vulcanizate properties}

The vulcanizate properties studied were tensile properties, tear strength, 300\% modulus, elongation at break, compression set and resilience. The results are shown in Table 7. It could be seen that there is no considerable difference between the mechanical properties of rubber blends prepared using fast/warm air dried skim laces and that prepared using conventionally dried skim laces. The mechanical properties of rubber vulcanizates depend on the network structure formed during vulcanization which is influenced by naturally occurring accelerators in the rubber, average molecular weight distribution of the rubber molecules and the compatibility of the components in rubber. Therefore, it could be inferred that drying of skim rubber in the drying system has not caused any detrimental effect on its vulcanizate properties of the $80 / 20$ blend of TSR/skim crepe laces.

\section{Conclusions}

An accelerated drying system was introduced to dry skim laces within a single day reducing the total drying time in a conventional drying system in natural air by more than $60 \%$. New drying system does not adversely affect the raw rubber properties of the skim laces. It was found that the temperature should be maintained at a range of 30 $34^{\circ} \mathrm{C}$, a temperature range slightly above the ambient temperature. Drying of skim laces above this temperature range deteriorated the raw rubber properties of skim laces. It was also shown that cure characteristics and vulcanizate properties of blends of TSR/skim rubber prepared using ambient air dried and warm air dried skim rubber have no significant differences in their rheological and vulcanizate properties. Therefore, drying of skim rubber using the newly introduced drying system at a temperature range of $30-34{ }^{\circ} \mathrm{C}$ could be recommended for accelerated drying of skim laces.

Table 7. Comparison of vulcanization properties of blends of warm air dried and ambient air dried skim rubber/TSR (20) sheet rubber blends

\begin{tabular}{lll}
\hline Property & Ambient air dried samples & Warm air dried samples \\
\hline Tensile strength (MPa) & 9.08 & 8.91 \\
Elongation @ break (\%) & 725 & 660 \\
Modulus @ 300\% (MPa) & 0.97 & 1.08 \\
Tear strength kN/m & 30.5 & 31.5 \\
Compression set $(\%)$ & 31.8 & 39.8 \\
Hardness, IRHD & 30.15 & 31.22 \\
Resilience 28 ${ }^{0} \mathrm{C}(\%)$ & 46.6 & 47.6 \\
\hline
\end{tabular}




\section{Acknowledgements}

The authors wish to thank for the encouragement and for the facilities provided by the management of Lalan Rubbers (Pvt.) Ltd. Special thanks are due to the staff at Bulathsinhale Centrifuged Latex Factory especially Messrs Ruwan, Samitha and Rohitha for their support extended in carrying out the experimental work.

\section{References}

Anon (2010). Plantation Sector Statistical Handbook (2010). Economic and Social Statistics of Sri Lanka, Ministry of Plantation Industries, Sri Lanka.

Bremayer, M, Pass, T, Muhlbauer, W, Amir, E J and Mulato, S (1993). Solar assisted smokehouse for the drying of natural rubber on small - scale Indonesian farms. Renewable Energy $\mathbf{3}$, No.8, $831-839$.

Bristow, G M (1990). Composition and cure behavior of skim block natural rubber, Technology 44, No.1, 21-30.

Jolly, P G (1987) Interim report on solar rubber drying in Sri Lanka. University of Queensland, St. Lucia, Queensland, Australia.

Mohd. Y H O and Sopian. K (1991). Energy conservation in rubber industry, Solar Energy Research Group, University of Kebanagssan, Malaysia. 43600, Bangi, Malaysia. $142-152$.

Monerasingha, N J and Basha, J M (1985). Proceedings of the Second Asian Conference on Technology for Rural Development. Kuala Lumpur, Malaysia, $4-7$.
Rao, P S R, Graham, D J and Muniandy, V (1985). Solar power boosted smokehouse. Proceedings of the $2^{\text {nd }}$ Asian Conference on Technology for Rural Development, Kuala Lumpur, Malaysia, 497 - 511.

Seneviratne, W M G and Sarath Kumara, P H (2003). Handbook of Rubber Vol. 2, Rubber Technology, Rubber Research Institute of Sri Lanka, Agalawatta, Sri Lanka.

Silaban, M, Sumarsono, Jerrino, S and Sri Mulato Grandegger, K (1990). Solar rubber sheet drier in Indonesia, Proceedings of 1-St World Renewable Energy Congress, Reading, U. K., 914 919.

Siriwardena, S, Siriwardena, T A S and Warnajith, A K D (2008). A new single day smoke drying system for efficient drying of sheet rubber. Proceedings of $2^{\text {nd }}$ Symposium on Plantation Crop Research, BMICH, Colombo, 16-17, October, 2008

Tharamalingam, R, Ponniah, W T, Koelmeyer, C and De Silva, K P N (1977). Journal Rubber Research Institute of Sri Lanka 54, 640-648.

Walpita, N C C, Gunaruwan, F and Laelwala, P (1984). Solar assisted crepe rubber drying. Proceedings International Rubber Conference Vol.2, Part II, Sri Lanka, 381 - 390.

Address for correspondence: Dr S Siriwardena, Head, of the Raw Rubber Process Development \& Chemical Engineering Dept., Rubber Research Institute of Sri Lanka, Telewala Road, Ratmalana, Sri Lanka.

e-mail: susantha.siriwardena@yahoo.com 